\title{
Escenificaciones de poder en el ceremonial de las aperturas de Cortes españolas del siglo $\mathrm{XIX}^{*}$
}

\author{
Oriol Luján ${ }^{1}$ \\ Universidad Complutense de Madrid \\ olujan@ucm.es
}

RESUMEN: Este texto tiene la voluntad de analizar los ceremoniales de las aperturas de Cortes españolas de los primeros tres cuartos del siglo XIX (18101874), como actos simbólicos de representación del poder. En estas páginas, se examinan las principales características del ritual, así como el papel de los sujetos participantes. Fundamentado en una metodología multidisciplinar, el estudio combina la influencia de la comunicación simbólica y el análisis de los conceptos utilizados en los discursos de apertura. El resultado pone de relieve la voluntad de la monarquía para presentarse como nexo de unión entre las instituciones parlamentarias y la población, conservando la Corona una posición autónoma. A pesar de que el ceremonial consolidó el papel central de la Corona, hay que destacar que también sirvió a los gobiernos como instrumento de control político y, en última instancia, ayudó a asentar el parlamentarismo.

PAlABRAS ClAVE: aperturas de Cortes; comunicación simbólica; monarquía; parlamentarismo; liberalismo; siglo XIX.

\section{Staging of power at the opening of the Spanish parliament during the nineteenth century}

ABSTRACT: This text analyses the ceremonies of the Spanish State Opening of Parliament during the first three quarters of the nineteenth century (1810-1874)

* Este trabajo forma parte de una investigación postdoctoral, vinculada a una ayuda Juan de la Cierva - Formación del Ministerio de Ciencia, Innovación y Universidades y al proyecto "La nación en escena: símbolos, conmemoraciones y exposiciones, entre España y América Latina (1890-2010)", HAR2016-75002-P, dirigido por Marcela García Sebastiani y Javier Moreno Luzón.

${ }^{1}$ ORCID iD: https://orcid.org/0000-0002-3941-3502.

Copyright: (C) 2019 CSIC. Este es un artículo de acceso abierto distribuido bajo los términos de una licencia de uso y distribución Creative Commons Reconocimiento 4.0 Internacional (CC-BY 4.0) 
as symbolic acts of the representation of power. The research examines the main characteristics of the ritual, as well as the role of the individuals taking part. Based on a multidisciplinary methodology, the study combines the influence of symbolic communication and the analysis of the concepts used in the opening speeches. The result highlights the will of the monarchy to present itself as a link between parliamentary institutions and population, in which monarchy retained its autonomous position. The ceremony consolidated the Crown's key role, but was also used by governments as an instrument of political control, which ultimately helped to establish parliamentarianism.

KEY WORDS: State openings of parliament; symbolic communication; monarchy; parliamentary studies; liberalism; nineteenth century.

CÓMO CITAR ESTE ARTÍCULO/CITATION: Luján, Oriol, «Escenificaciones de poder en el ceremonial de las aperturas de Cortes españolas del siglo XIX», Hispania, 79/261 (Madrid, 2019): 99-126. https://doi.org/10.3989/hispania.2019.004.

\section{Presentación}

Las instituciones parlamentarias nacen con la misión de representar a los ciudadanos y a sus intereses. En España se implementaron por primera vez con la introducción del liberalismo político y su concreción en las Cortes de Cádiz (1810-14). Según instituía el artículo 27 de la Constitución, «las Cortes son la reunión de todos los Diputados, que representan la Nación, nombrados por los ciudadanos en la forma que se dirá» ${ }^{2}$. No se trata de ninguna particularidad, más bien de una característica atribuible al propio sistema parlamentario ${ }^{3}$, pero desde el primer momento que surgió el parlamentarismo en la monarquía española se concibió como sistema de representación de la nación, entendida como comunidad política soberana ${ }^{4}$.

Otra cuestión sería reflexionar sobre el grado de representatividad del sistema parlamentario en función del sistema electoral utilizado. De hecho, la historiografía ha abordado el estudio de la representatividad de las instituciones parlamentarias, y las posibles fórmulas utilizadas para representar e integrar a

\footnotetext{
${ }^{2}$ Constitución política de la Monarquía Española, 1812, disponible en: http://www. congreso.es/docu/constituciones/1812/ce1812_cd.pdf [consultado el 12 de julio de 2018].

${ }_{3}$ En la teoría constitucional del Estado, la nación es concebida como sujeto unitario que está compuesto de individuos igualmente considerados. Véase VARELA SUANZES-CARPEGNA, 2011. Complementariamente a esta aportación y desde el análisis de la representación política, también se consideran las vinculaciones entre representación y soberanía nacional en GARRORENA, 1991.

${ }^{4}$ PORTILLO, 2002: 471.
} 
la nación, desde diferentes y múltiples vertientes, pero una de las perspectivas quizás con más recorrido en el análisis del siglo XIX es aquella que considera el grado en que la sociedad pudo intervenir en la política a partir del estudio de la extensión del derecho al voto. Este punto de vista se ha traducido en la valoración y evolución del sufragio censitario ${ }^{5}$, así como en la reflexión sobre la caracterización, las modificaciones y las consecuencias de las leyes electorales ${ }^{6}$.

Otra vía de aproximación a la representación política de las instituciones parlamentarias se produce con el análisis de la composición social de los parlamentos. Es decir, incidiendo en la relación entre la composición interna de la cámara y la evolución social de la colectividad que representan ${ }^{7}$. Estos planteamientos pueden ser insuficientes, ya que un parlamento no tiene razón de ser representativo solo porque refleja la composición social de una sociedad si no lo hace a la vez con los distintos intereses de la misma.

Para complementar este tipo de enfoques emergen otros aspectos a los que prestar atención, como las relaciones de representación entre gobernantes y gobernados, ya sea considerando la capacidad de los últimos de incidir en las decisiones de los primeros o subrayando el absentismo de los diputados que tiende a implicar una desconexión con relación al electorado, entre otras contingencias ${ }^{8}$. Otra posibilidad es el estudio de los instrumentos de influencia de la sociedad hacia las instituciones políticas. Ejemplo de ello son las peticiones ciudadanas 9 .

Al fin y al cabo, el estudio de la representatividad de las instituciones parlamentarias es una manera de aproximarse a una de las líneas de investigación más arraigadas en la historiografía española actual: el proceso de nacionalización. Después de unas décadas de focalización del debate en la supuesta debilidad o fortaleza de este proceso, en los últimos años la investigación se ha renovado. Por un lado, el giro loca $1^{10}$ ha permitido repensar la construcción de la nación a partir de la relación con las identidades regionales. Por otro lado, la apertura de nuevas líneas - como la construcción, difusión y exhibición de símbolos nacionales o la celebración de conmemoraciones patrióticas — ${ }^{11}$ ha enriquecido el debate.

\footnotetext{
${ }^{5}$ SANTIRSO, 2008.

${ }^{6}$ Entre otros, PRESNO LINERA, 2013. ESTRADA SÁNCHEZ, 1999. FERNÁNDEZ DOMÍNGUEZ, 1992.

${ }^{7}$ Resultan muy interesantes los análisis comparados a nivel europeo de Maurizio Cotta y Heinrich Best: BEST y COTTA, 2000; 2007.

${ }^{8}$ LUJÁN, 2017.

${ }^{9}$ KNIGHTS, 2009: 35-57. PALACIOS, 2014.

10 Entre otros, NÚÑEZ SEIXAS, 64 (Madrid, 2006). CALATAYUD, MILLÁN y ROMEO, 2009. Un estado de la cuestión en VEIGA, 108 (Madrid, 2017): 285-302.

${ }_{11}$ MORENO LUZÓN y NÚÑEZ SEIXAS, 2017. GARCÍA SEBASTIANI y MARCILHACY, 52/3 (Essex, 2017): 731-763.
} 
Precisamente, el estudio de las festividades permite aproximarse a la representatividad de las instituciones políticas desde la trascendencia de la comunicación simbólica. Distintas disciplinas, como la historia, la antropología, la sociología o la semiótica se han acercado al estudio de los símbolos, rituales y ceremonias con múltiples objetivos, aunque frecuentemente para analizar la organización del poder escondida detrás de este tipo de celebraciones ${ }^{12}$. Las investigaciones sobre el significado de la fiesta cuentan ya con una importante tradición a sus espaldas, especialmente en la historiografía francesa y con ánimo de preguntarse sobre la politización de la sociedad y sobre las relaciones de poder entre gobernantes y gobernados ${ }^{13}$. También la fiesta ha despertado un notable interés en nuestra historiografía ${ }^{14}$, renovándose en los últimos años con aportaciones de la historia cultural y la historia del arte, y con la monarquía como principal objeto de estudio ${ }^{15}$. Por el contrario, las festividades de las instituciones parlamentarias no cuentan aún con un arraigo relevante.

Aquí nos interesa aproximarnos a las festividades en torno a las instituciones parlamentarias como formas de legitimación del nuevo sistema implementado con el liberalismo. Se trata de explorar las transformaciones introducidas en estos actos en búsqueda de aceptación y consenso para el nuevo sistema social y político. Su escenificación revelaba una serie de voluntades políticas que trascendían el momento de ejecución e implicaban unas pautas de relación entre los mismos actores políticos y entre ellos y la sociedad.

La presente aportación tiene la ambición de inscribirse en estas últimas aportaciones que estudian las festividades y conmemoraciones nacionales como formas simbólicas de representación política, que a la vez nos permiten ahondar en los condicionantes del proceso de nacionalización. Concretamente, se considerará la conformación y el simbolismo del acto de apertura de Cortes y los cambios producidos en este evento entre 1810, sus inicios, y 1874, cerrando una etapa antes de la Restauración. El estudio se fundamentará en una metodología multidisciplinar. Por un lado, tendrá en cuenta la influencia de la comunicación simbólica de las festividades. Es decir, analizará la forma cómo se organizaron y desarrollaron estos actos y los cambios que presentaron, con la finalidad de reflexionar sobre sus implicaciones sociales y políticas. Se fijará entonces la atención en la construcción del ritual y en su significación, a partir de los actores implicados, en las funciones que éstos desarrollaron y en las relaciones establecidas entre los diversos sujetos y colectivos participantes. Para

${ }^{12}$ Entre otras publicaciones, me interesa resaltar por sus conexiones con la política KERTZER, 1988. Y por sus implicaciones en el ámbito público HANDELMAN, 1990.

${ }_{13}$ Desde OZOUF, 1976, pasando por IHL, 1996, hasta los más recientes, como MARIOT, 1 (París, 2008): 113-139.

${ }_{14}$ Ofrece un interesante estado de la cuestión SAN NARCISO, 21 (Madrid, 2014): 191-207.

15 A destacar, entre otros, LUENGO, 2013. También ROCA, 86 (Valencia, 2016): 71-90. 
documentar estos cambios se trabajará con los distintos reglamentos de las cámaras parlamentarias, así como con la información que los diarios de la época recogían.

Por otro lado, el estudio se fundamentará en una reflexión influida por la línea de investigación ligada al giro lingüístico ${ }^{16} \mathrm{y}$ la historia del lenguaje y de los conceptos. Dado que la construcción de la realidad y la propia experiencia social dependen del marco lingüístico de cada momento, esto implica que los significados de las palabras evolucionan y cambian de significado ${ }^{17}$. He aquí la importancia de conocer las ideas asociadas a determinados conceptos, que nos pueden ayudar a entender la evolución de la integración de la población en la política oficial. Mediante la consulta de los Diarios de Sesiones de Cortes se analizarán las variaciones en el tipo de lenguaje utilizado en los discursos de apertura de Cortes - cómo se transforma el uso de determinados conceptos, de manera que unos tienden a desaparecer y otros a emerger-, con el objetivo de comprender exactamente el significado atribuido por los dirigentes políticos a términos como «pueblo», «nación» y «representante».

Por consiguiente, en este trabajo se analiza el proceso de nacionalización desde arriba (el papel de la Corona y de los parlamentarios en las aperturas de Cortes, así como las relaciones de poder trazadas entre ambas instituciones), pero con la mirada puesta hacia abajo (la concepción transmitida en los discursos sobre los españoles y su capacidad de poder político). Estas reflexiones arrojarán luz sobre las voluntades de representación de los parlamentarios y, por ende, sobre las relaciones entre las instituciones parlamentarias y la población.

\section{LAS PRIMER AS APERTURAS DE CORTES COMO ESPEJO DE LA DISPUTA DE LEGI- TIMIDADES DE PODER}

A pesar de que el palacio del Congreso de los Diputados no fue inaugurado hasta 1850 , y de que la sede parlamentaria fue itinerante en sus primeros años, desde las Cortes de Cádiz (1810-14) se pensó en una ceremonia de apertura. En el texto constitucional no se llegó a concretar un acto con un protocolo manifiestamente identificable. Sin embargo, se diseñaron las principales características en las que tenía que basarse la inauguración del curso político: un evento protagonizado por el rey y con un discurso leído por él, que dispondría de plena capacidad para decidir el contenido del mismo ${ }^{18}$. Se consideró entonces que la Corona tendría un destacado protagonismo en este ritual. Incluso en la primera

\footnotetext{
16 CLARK, 2004. SPIEGEL, 2005.

17 FERNÁNDEZ SEBASTIÁN y FUENTES, 2002.

${ }^{18}$ Constitución política de la Monarquía Española (1812), disponible en: http://www. congreso.es/docu/constituciones/1812/ce1812_cd.pdf [consultado el 12 de julio de 2018].
} 
mitad del siglo XIX, con el palacio del Congreso aún por inaugurar, en la mayoría de las ocasiones el acto se desarrolló en residencias de la Corona, como fue el caso del Palacio del Retiro. Cabe entender este distinguido papel como una herencia de la organización del poder en el Antiguo Régimen y de su control absoluto por parte del monarca, pero también como resultado del nuevo contexto social y político liberal, con el asentamiento de la vía monárquica constitucional que se extendió por la Europa libera ${ }^{19}$.

Estas circunstancias certifican que los primeros decenios del siglo XIX fueron un período de disputa entre monarquía e instituciones parlamentarias. Se debatían dos legitimidades: la del principio monárquico como sujeto de derecho natural y la de las instituciones parlamentarias como receptoras de la soberanía nacional con la llegada del liberalismo ${ }^{20}$. Las aperturas de Cortes, como ceremoniales rituales, escenificaban este choque de legitimidades y descubrían las relaciones de autoridad creadas. La monarquía continuó ejerciendo un papel protagonista, pero a la vez las instituciones parlamentarias empezaron a discutirle la preeminencia.

Fijémonos en cómo se tradujo este imaginario en las primeras aperturas de Cortes. En ausencia del rey, la Regencia actuó en su representación (asumiendo el poder ejecutivo), configurada bajo el control del poder legislativo que constituían las Cortes ${ }^{21}$. Asimismo, la Regencia se encargó de fijar el ceremonial de apertura y el procedimiento de toma de posesión de los diputados. Incluso su presidente era quien conducía el acto y ofrecía un discurso inaugu$\mathrm{ral}^{22}$. A la postre, los diputados se reunían, antes que nada, en el palacio de la Regencia en Cádiz. Eso es, la institución que personificaba la monarquía encauzaba la sesión y, por lo tanto, la Corona conservaba de esta forma relevantes facultades.

Debemos entender estos condicionantes, como nos indica Juan Sisinio Pérez Garzón, de acuerdo con el contexto del momento, marcado por el tránsito entre el Antiguo Régimen y el liberalismo ${ }^{23}$. La soberanía nacional no se había proclamado aún, instituciones como la Inquisición se mantenían vigentes y el Estado era confesional católico. En efecto, que la sesión de apertura del 24 de setiembre de 1810 se celebrase en la iglesia parroquial de la isla de León de Cádiz para «implorar la asistencia divina por medio de una misa» ${ }^{24}$ no tenía tanto que ver con la presidencia del obispo de Orense, Pedro Que-

19 MILLÁN, 2016.

${ }^{20}$ GARCÍA MONERRIS, MORENO SECO y MARCUELLO BENEDICTO, 2013: 1.

${ }^{21}$ PÉREZ GARZÓN, 2007: 380-390.

22 ARTOLA, 1 (Madrid, 1991): 69.

${ }^{23}$ PÉREZ GARZÓN, 2007.

${ }^{24}$ Diario de Sesiones del Congreso de los Diputados (DSC de aquí en adelante): legislatura 1810-1813: 2, disponible en línea en: https://app.congreso.es/est_sesiones/ [consultado el 8 de febrero de 2019].

Hispania, 2019, vol. LXXIX, n 261, enero-abril, págs. 99-126, ISSN: 0018-2141, e-ISSN: 1988-8368 
vedo, ni con la presencia de un tercio de eclesiásticos entre los diputados ${ }^{25}$, como con el espíritu confesional de la época. Incluso la fórmula de toma de posesión por parte de los diputados estaba vinculada a la condición de ciudadano católico ${ }^{26}$ :

¿Juráis la santa religión católica, apostólica, romana, sin admitir otra alguna en estos Reinos? ¿Juráis conservar en su integridad la Nación española, y no omitir medio alguno para libertarla de sus injustos opresores? ¿Juráis conservar a nuestro amado soberano el Sr. D. Fernando VII todos sus dominios, y en su defecto a sus legítimos sucesores, y hacer cuantos esfuerzos sean posibles para sacarlo del cautiverio y colocarlo en el Trono? ¿Juráis desempeñar fiel y legalmente el encargo que la Nación ha puesto a vuestro cuidado, guardando las leyes de España, sin perjuicio de alterar, moderar y variar aquellas que exigiese el bien de la Nación ${ }^{27}$ ?

No solo era el contenido del juramento que concernía la unión de la condición de ciudadano a la de creyente católico - situación que salvo el paréntesis del Sexenio Democrático no cambió hasta la Segunda República-, sino también el hecho de efectuar dicho juramento con el libro de los Santos Evangelios delante. Según el reglamento de 24 de noviembre de 1810 el juramento de diputados y regentes se tenía que hacer «poniendo la mano sobre los santos Evangelios, hincados de rodillas y al frente de una cruz colocada en la mesa del presidente $\rangle^{28}$.

Con la introducción del liberalismo en España, mediante su concreción en el proyecto gaditano, apareció el concepto de nación como entidad política soberana que encarnaba la unión de ciudadanos libres y que estaba representada políticamente por las Cortes. Por el contrario, el rey perdía este tipo de representatividad y su poder emanaba del reconocimiento de la nación, con lo que tuvo que resituarse y repensar su pape ${ }^{29}$. Da prueba de ello el tipo de relación trazada entre políticos y sociedad en el ceremonial de 1810. La comitiva de diputados fue recibida por la población gaditana con vivas a la nación, además de recibir flores y poesías que versaban sobre la libertad y los nuevos porvenires que abrían las Cortes $^{30}$. El diputado Agustín Argüelles resaltaba, en su crónica de las Cortes, el ambiente de esos momentos, con «un pueblo conmovido» con voluntad de dar por acabada su sumisión y de tomar las riendas del

25 SUÁREZ, 1982: 47. CASALS, 2014: 82.

26 ALONSO, 2007.

${ }^{27}$ DSC: legislatura 1810-1813: 2, disponible en: https://app.congreso.es/est_sesiones/ [consultado el 8 de febrero de 2019].

${ }^{28}$ Reglamento para el gobierno interior de las Cortes, 1810, disponible en: http://www. congreso.es/docu/blog/reglamento_cortes_1810.pdf [consultado el 12 de julio de 2018].

29 ARTOLA, 1 (Madrid, 1991): 115.

${ }^{30}$ COMENGE, 1909, vol. 1: 215. 
poder $^{31}$. No hubo discurso del rey, por su ausencia, aunque no estuvo del todo ausente: un gran retrato suyo tutelaba la sesión ${ }^{32}$.

En efecto, el ceremonial concedió al monarca una destacada posición conforme se fue definiendo. Siguiendo el capítulo XV del reglamento de las Cortes de 1813, una representación de treinta diputados tenía que recibir al rey a su 1legada a la sede parlamentaria y acompañarlo al trono mientras los representantes y los allí presentes le acogían en pie. Con todo, el rey tenía que prestar juramento (a la Constitución), reconociendo así la soberanía nacional, a la vez que era el presidente de la cámara quien se dirigía al rey y éste solo podía contestar con un breve discurso ${ }^{33}$. Eso es, el rol del monarca se estaba redefiniendo, en un segundo plano y a la sombra de los representantes políticos.

Ante la ausencia de Fernando VII del territorio español en los primeros tiempos del liberalismo, este ceremonial no tuvo lugar propiamente hasta el Trienio Liberal (1820-23) ${ }^{34}$. La dialéctica entre el poder de origen divino y la soberanía nacional no se había confrontado todavía en el ritual de apertura. No resulta extraño que la concreción del acto no fuera tal y como se había ideado por las Cortes de Cádiz, que suponían que el monarca aceptaría su nuevo rol según las pautas de la monarquía constitucional. Por el contrario, Fernando VII no estaba dispuesto a reconocer la soberanía de la nación.

Como han demostrado Encarna y Carmen García Monerris, la reinstauración del absolutismo fernandino en 1814 supuso para la Corona la necesidad de dialogar con la realidad revolucionaria previa, ya que no se podía volver sin más al Antiguo Régimen. Eso se tradujo en un intenso rechazo a la obra gaditana por parte del rey y, cuando en 1820 tuvo que jurar la constitución liberal, lo hizo sin reconocerla en sus acciones. Las autoras lo ejemplifican con la gestión del patrimonio real. Avanzándose en la cesión de patrimonio era el rey quien decidía cómo y cuándo las posesiones tenían que pasar a la administración pública, no las instituciones parlamentarias ${ }^{35}$. En otras palabras, Fernando VII quería dictaminar el ritmo de las acciones, por lo que no reconocía la soberanía nacional.

Lo ilustra un discurso en la apertura de Cortes lleno de recelo hacia las instituciones parlamentarias ${ }^{36}$. Sus palabras en 1821 ponían de relieve la persisten-

31 ARGÜELLES, 1835, vol. 1: 124-127.

32 COMENGE, 1909, vol 1: 223.

${ }_{33}$ Reglamento para el gobierno interior de las Cortes, 1813, disponible en: https://drive. google.com/file/d/0B27DzfbcyPNBQW9hd3RhOG02a0E/view [consultado el 12 de julio de 2018].

${ }^{34}$ En relación con la organización de las aperturas de Cortes durante el Trienio Liberal, MEDINA, 2005: 129-133.

${ }^{35}$ GARCÍA MONERRIS y GARCÍA MONERRIS, 2015: 51-53.

${ }^{36}$ LA PARRA, 2011: 59. Sigan las actuaciones de conspiración del rey en LA PARRA, 2018: 399-474.

Hispania, 2019, vol. LXXIX, n 261, enero-abril, págs. 99-126, ISSN: 0018-2141, e-ISSN: 1988-8368 
cia de una concepción del poder de naturaleza divina. Tenía que mostrarse conforme con el rol desempeñado por los diputados, como representantes políticos, pero lejos de reconocer su legitimidad fundamentada en la soberanía nacional que contemplaba la Constitución de Cádiz, Fernando VII consideraba que su poder tenía un origen supremo y, por ende, no reconocía otra autoridad terrenal que la suya propia:

Al verme rodeado por segunda vez de los dignos representantes de esta Nación heroica que tantas y tan relevantes pruebas tiene dadas de su amor y adhesión a mi Real persona, mi corazón conmovido no puede menos de dar gracias al Todopoderoso, que, habiéndome restituido al Trono de mis mayores por el valor y constancia de mis fieles súbditos, se ha dignado consolidarle dándole por base la Constitución sancionada por las Cortes extraordinarias ${ }^{37}$.

No era la nación representada en Cortes quien de acuerdo con su soberanía ratificaba la carta magna y le reconocía como soberano, sino que era el poder divino que encarnaba el monarca quien tenía capacidad para establecer el texto constitucional como base legislativa. En consecuencia, el parlamento era visto como un simple organismo asesor. Esta perspectiva entraba en conflicto con la concepción de soberanía nacional que el artículo 3 del texto gaditano disponía ${ }^{38}$, ya que el monarca ejercía un rol que iba más allá de un papel simbólico.

Además, en el mismo discurso no apareció referencia alguna a los ciudadanos, como individuos soberanos, a pesar de que la Constitución de 1812 los contemplaba como encargados de nombrar a los representantes políticos ${ }^{39}$. Por el contrario, mencionó a «los pueblos». No se debe interpretar como la expresión adoptada cada vez más a partir de entonces por los sectores liberales progresistas y avanzados como sinónimo de los extractos sociales más humildes ${ }^{40}$, sino como resultado de una visión orgánica de la sociedad que implicaba una percepción comunitaria y no individualista de la nación y al mismo tiempo paternalista. Sin ir más lejos, la perspectiva de ciudadanía vinculada a la propiedad y al régimen censitario empezaba a reunir no pocos adeptos entre los representantes de Cádiz, aunque finalmente no se concretó en el modelo de ciudadanía aplicada, mediante un sufragio universal indirecto de amplia base ${ }^{41}$.

${ }^{37}$ DSC: legislatura de 1821: 18-19, disponible en: https://app.congreso.es/est_sesiones/ [consultado el 8 de febrero de 2019].

38 Versaba así: «La soberanía reside esencialmente en la Nación, y por lo mismo pertenece a ésta exclusivamente el derecho de establecer sus leyes fundamentales».

39 Constitución política de la Monarquía Española (1812), disponible en: http://www. congreso.es/docu/constituciones/1812/ce1812_cd.pdf [consultado el 12 de julio de 2018].

40 ÁlVAREZ JUNCO, 28 (Leioa, 2004): 88-89.

${ }^{41}$ SIERRA y PEÑA, 2012. 
También se hallaba citado en el discurso inaugural el término «nación»o «nación española», con implicaciones parejas. Al igual que la voz «pueblo», se usaba para designar al conjunto de la población desde una posición de sumisión al poder político, con el rey en la cúspide. Desde su punto de vista no se identificaba como sujeto político, sino como conjunto de individuos sometidos a los dirigentes:

... pero no debo callar hoy al Congreso, como principal encargado por la misma en la conservación de la inviolabilidad que quiere se guarde a su Rey constitucional, que aquellos ultrajes y aquellos insultos no se hubieran repetido segunda vez si el Poder ejecutivo tuviese toda la energía y vigor que la Constitución previene y las Cortes desean. La poca entereza y actividad de muchas autoridades ha dado lugar a que se renueven tamaños excesos; y si siguen, no será extraño que la Nación española se vea envuelta en un sinnúmero de males y desgracias; confío que no será así, si las Cortes, como debo prometérmelo, unidas íntimamente a su Rey constitucional, se ocupan incesantemente en remediar los abusos, reunir la opinión y contener las maquinaciones de los malévolos, que no pretenden sino la desunión y anarquía ${ }^{42}$.

En resumen, Fernando VII no reconocía la autoridad derivada de la soberanía nacional, así que aprovechaba los ceremoniales de apertura de Cortes para hacer valer su posición de poder. De hecho, aunque el discurso lo había escrito el rey - o sus allegados en su nombre - el encargado de entregárselo era el capitán de guardias de la real persona y mayordomo mayor. Simbólicamente quería representar la preeminencia del rey y de su entorno cortesano con atribuciones de poder de origen divino, aún por encima de los políticos, como representantes de los poderes terrenales. En todo caso, no debe confundirse la voluntad del rey con la de las Cortes. Ya entonces el presidente del congreso respondía a la intervención del monarca y, además, se constituyó una comisión de diputados para analizar y contestar el discurso del monarca, aunque en opinión del diputado Antonio Alcalá Galiano la discusión parlamentaria era «breve y de ningún empeño» ${ }^{43}$.

\section{LOS INICIOS DEL CEREMONIAL CON LA REINA REGENTE}

Si en los primeros compases del liberalismo en España el rey utilizaba el ceremonial de apertura de las Cortes para evidenciar la distancia que le separaba con las instituciones parlamentarias, a partir de la década de 1830 ese

${ }^{42}$ DSC: legislatura de 1821: 18-19, disponible en: https://app.congreso.es/est_sesiones/ [consultado el 8 de febrero de 2019].

${ }^{43}$ CAMPOS, 1955. 
momento fue interpretado por la Corona como una oportunidad para robustecer su posición en el régimen liberal. Ante la progresiva consolidación del ritual como una ocasión para la relación entre instituciones parlamentarias y población, la monarquía aprovechó la ocasión para presentarse como vínculo indispensable entre ambas. No es casual que jugara ese papel, dado el contexto histórico. La Primera Guerra Carlista (1833-40) ponía en tela de juicio la legitimidad de la futura Isabel II, entonces suplida por su madre, la reina regente María Cristina. Sin duda, la necesidad de unión entre los políticos liberales y la línea sucesoria isabelina para derrotar la amenaza carlista ayuda a entender la forma en que se configuró la celebración, con la reina como símbolo de consenso del conjunto de fuerzas políticas liberales.

Fue a partir de entonces que el ritual se consolidó, entrañando unas relaciones simbólicas muy indicativas del papel de los distintos actores, empezando por la Corona, que se situó en el epicentro del acto y aprovechó esta condición para prodigarse. Como en los ceremoniales desarrollados en las Cortes europeas modernas ${ }^{44}$, donde el protagonismo giraba en torno al rey, mayor era la distinción cuanto más cerca uno estaba; así uno le podía mostrar sus respetos. También las aperturas de Cortes en el liberalismo se instauraron como rituales que reprodujeron estas relaciones de poder ${ }^{45}$.

En primer lugar, se instituyó un desfile público con la única participación de la monarquía y de sus sirvientes. En la comitiva no estaba invitado ningún representante político. Inicialmente, la necesidad de desplazamiento desde el Palacio Real hasta el Palacio del Buen Retiro propició la situación. Aprovechando esta circunstancia, el trayecto se transformó en una marcha real ${ }^{46}$. La Reina regente, y con posterioridad Isabel II, recorrían el centro de Madrid en carruaje, pasando por la calle Mayor y por la Puerta del Sol hacia el destino final (primero el Palacio del Retiro y más tarde el Palacio del Congreso de los Diputados).

Estas rutas evocan y reconstruyen los desfiles de la monarquía y la Corte por las calles de Madrid en época moderna. Como entonces, los distintos miembros de la casa real se exhibían en público. En la inauguración del palacio del Congreso en 1850, por ejemplo, en el desfile participaron doce carruajes con gentilhombres de la cámara, mayordomos, camareras, caballerizos, damas y nobles de la Corte y miembros de la familia real ${ }^{47}$. Así como en la época

${ }^{44}$ Una reflexión sobre los ceremoniales en las Cortes modernas en WELLER, 13 (Pamplona, 2010): 9-33.

${ }_{45}$ Sobre la evolución y configuración de las festividades en torno a la monarquía española en el contexto del primer liberalismo y la influencia de la comunicación simbólica de Antiguo Régimen véase LUENGO, 2013.

${ }^{46}$ MEDINA, 2005: 129-133.

47 El Popular, 1 de noviembre de 1850: 1. 
moderna, estos participantes se disponían en orden jerárquico, de manera que la reina y su esposo iban en última posición, como reflejo de la estratificación social $^{48}$.

El objetivo de este tipo de ceremoniales en el Antiguo Régimen era conectar con la población, a la vez que reproducir la posición de preeminencia social de la monarquía. Con la aclamación pública se obtenía reconocimiento a la posición de poder y los desfiles durante las aperturas de Cortes del siglo XIX tendían a reproducir esta estratificación social. Buscando la aprobación de la población en un nuevo contexto social y político donde la monarquía tenía que resituarse y captar legitimidad frente a la opción carlista, la Corona se exhibía para relacionarse con la población y ganar su favor. Con todo, sus vínculos 1legaban desde la imposición y con una participación pasiva. Sin ir más lejos, los vecinos estaban obligados a adornar sus casas con colgaduras y a no quitarlas hasta el regreso de la familia real. Así lo notificaba El Diario de Avisos de Madrid en 1835:

... lo hago notorio a los vecinos a quienes incumba llenar este deber, seguro de que así ellos como los demás habitantes de Madrid acreditarán en tan fausto día su lealtad y gratitud a nuestra Reina Doña Isabel II y a su augusta madre ${ }^{49}$.

A pesar de ello, es evidente que estas circunstancias facilitaban la expectación social. Al menos lo indica la duración de aproximadamente una hora de trayecto para hacer unos tres kilómetros en carruaje. Aunque por lo general la implicación de la población se limitaba a la observación y veneración, sin posibilidad de intervención directa, hay indicios no solo de aceptación del modelo de ceremonial trazado, sino de asimilación del sistema que mantenía la monarquía en una posición preeminente. Así, y a diferencia de los primeros compases del liberalismo español, los vítores pronunciados en este tipo de actos ya no se focalizaban de manera categórica en la nación. Por aquel entonces, también la monarquía había adquirido relevancia. Así lo indicaba la crónica de 1835 de $E l$ Eco del Comercio:

Vítores entre los que sobre todo resonó con más entusiasmo el de viva la madre del pueblo, no cabiéndole pequeña parte de estos vítores al señor Mendizábal, en particular, y al gobierno en general ${ }^{50}$.

No es trivial la referencia «madre del pueblo» para referirse a la reina regente. Simboliza la representación de toda la población y, por extensión, entraña una vinculación de la monarquía con el pueblo como elemento

\footnotetext{
48 JURADO, MARÍN PERELLÓN, DE LOS REYES y DEL RÍO, 1991.

49 Diario de Avisos de Madrid, 16 de noviembre de 1835: 1.

${ }^{50}$ El Eco del Comercio, 17 de noviembre de 1835: 3.
} 
evidente de nacionalización. El hecho de aclamar a una persona expresa los sentimientos de un grupo públicamente, y éste da así su aprobación o desaprobación. Este tipo de actuaciones articulan lo que a la liturgia simbolizan actos de fidelidad al señor ${ }^{51}$. Eso es, aprobación y legitimidad. Las aclamaciones populares son actos emotivos y con una larga tradición histórica, que no necesariamente implican un proceso de democracia directa ${ }^{52}$, pero que demandan de una participación social indudable.

En opinión de Jordi Roca, el entusiasmo popular en las fiestas cívicas monárquicas en España, que ha estudiado durante la década de 1830, respondía al ambiente creado por los ayuntamientos en dichos actos y no a la popularidad de la institución. Además, apunta que la monarquía constitucional se banalizó en asimilar formas festivas tradicionales a sus fiestas públicas ${ }^{53}$. A mi modo de ver, el mérito de la monarquía isabelina, como se continuará demostrando, es que consiguió integrar elementos simbólicos de la fiesta monárquica moderna a la nueva realidad liberal, manteniendo así un espacio de poder muy significativo y a la vez efectivo, porque conectaba con la población en un momento crucial para su supervivencia. Aunque fuera desde la pasividad o la complicidad social, la monarquía era aprobada por la población como entidad íntimamente ligada a las instituciones parlamentarias y a la nación y lo hacía desde una posición preeminente en el poder.

Simboliza y corrobora esta disposición el intencionado uso de los atuendos y sus colores. En la sesión de apertura de las Cortes de 1835 la reina regente iba vestida de «gran gala». Era una forma de promover la distinción de la institución entre la sociedad ${ }^{54}$. En esa ocasión vestía un manto de terciopelo negro bordado de plata y una diadema de brillantes ${ }^{55}$. El terciopelo, la plata y los brillantes son todos ornamentos de calidad y distinción, por su alto precio, mientras el color negro infunde autoridad y poder.

Así como la monarquía también los representantes políticos usaban los ropajes como símbolo de distinción. Según el reglamento del Estamento de Procuradores de $1834^{56}$, los procuradores tenían que vestir de negro en las sesiones regias, «excepto los que tengan uniforme y prefieran usarlo». El color negro, como decíamos, ha sido tradicionalmente símbolo de autoridad — los jueces, por ejemplo - y de elegancia, pero especialmente en el siglo XIX se

51 CHÁVARRY, 2002: 97.

52 DE LA FUENTE, 2000: 88.

53 ROCA, 86 (Valencia, 2016): 79 y 90. Inspirándose en MARIOT, 1 (París, 2008): 113-139.

${ }^{54}$ SAN NARCISO, 108 (Madrid, 2017): 217.

55 El Eco de Comercio, 17 de noviembre de 1835: 2.

${ }^{56}$ Reglamento para el régimen y gobierno del Estamento de Procuradores a Cortes, 1834. Disponible en: http://www.congreso.es/docu/constituciones/1834/reglamento.pdf [consultado el 12 de julio de 2018]. 
asociaba a los uniformes de la autoridad y a la respetabilidad ${ }^{57}$. El uniforme, a su vez, también ofrece una imagen de autoridad y poder: actúa como símbolo de estatus social ${ }^{58}$. En el caso de los militares, el uniforme refleja el rango y, por extensión, exhibe posición social. No es baladí indicar que cerca de una cuarta parte de los procuradores del Estatuto Real pueden ser considerados como militares ${ }^{59}$. Al igual que la monarquía, también los políticos querían resaltar su estatus entre la población, adquiriendo reconocimiento y representando su posición de poder.

Corona y políticos compartían protagonismo, de acuerdo con el sistema de monarquía parlamentaria que se estaba configurando, con un modelo de soberanía compartida entre las Cortes y la monarquía que la Constitución de 1837 insinuó y que el texto de 1845 introdujo y consolidó. Los políticos concedían espacio a la monarquía en el poder político y en sus ceremoniales de acuerdo con el sistema, mientras la monarquía se servía de ellos para representar su posición política y social y fortalecerse como institución vinculada a la idea de nación.

Además, las bases del proyecto liberal no fueron estáticas, sino cambiantes. La década de 1830 fue convulsa, con la Primera Guerra Carlista (1833-40) y las rebeliones para una mayor transformación social y política. Estos intensos movimientos incidieron en el pensamiento de los principales dirigentes y partidos políticos, con la consolidación de una visión del poder que rechazó la base de la soberanía nacional - conceder el poder a la multitud se percibía como un peligro - y se fundamentó en un modelo social y político basado en la ciudadanía propietaria - implicando una menor participación social en la política con el rasero del sufragio censitario - y en el mantenimiento del orden público. Como ha indicado María Cruz Romeo, en la década de 1830 se revisó el proyecto gaditano con la conformación de un nuevo liberalismo ${ }^{60}$. Únicamente los liberales más avanzados se desmarcaron de este diagnóstico que compartían conservadores y progresistas para alejar las corrientes más radicalizadas de las instituciones parlamentarias.

\section{LA CONSOLIDACIÓN DEL CEREMONIAL DURANTE EL REINADO DE ISABEL II}

Con estos condicionantes, el ceremonial se afianzó entre la década de 1830 y la de 1840, uniendo su esencia a la participación de la Corona. En efecto, el desfile de la monarquía era su seña de identidad, que con la inauguración del

\footnotetext{
57 PASTOREAU y SIMONNET, 2014.

58 JOSEPH y ALEX, 77/4 (Chicago, 1972): 719-730.

59 CASALS, 2014: 186.

${ }^{60}$ ROMEO, 1998.
} 
palacio del Congreso de los diputados en 1850 quedó establecido desde el Palacio Real hasta la cámara baja, pasando por la calle Mayor y la Puerta del Sol ${ }^{61}$. El protagonismo de la monarquía en las aperturas de Cortes no se limitaba solo a la marcha por las calles, sino que continuaba en el interior de las instituciones parlamentarias. A su llegada al Congreso una delegación de los representantes políticos recibía a la reina y a su comitiva para entrar juntos en el edificio. La posición de entrada y de asiento revelaba de nuevo la jerarquía entre los distintos participantes. En primera posición iban los representantes políticos, mientras los ministros del gobierno lo hacían al mismo tiempo que los jefes de palacio, acompañando a la reina. En el interior del hemiciclo, la reina disponía de trono, que era flanqueado por su esposo y por los ministros. Justo detrás se situaban los jefes de palacio y demás miembros de la real servidumbre. Eso es, únicamente de entre los políticos, los ministros del gobierno se podían equiparar al nivel de la monarquía.

Completa el papel preeminente de la monarquía en el ceremonial de apertura de Cortes el mantenimiento de ritos propios de esta institución. Por ejemplo, el hecho de que el presidente del Consejo de Ministros besaba la mano de la reina y le entregaba el discurso para que lo leyera. El ritual del besamanos nos lleva de nuevo a las tradiciones modernas. Se trataba de un rito reservado a las personalidades más distinguidas de la sociedad y servía para mostrar respeto y homenaje a la monarquía. Es decir, participar en ellos era símbolo de distinción y de reconocimiento social ${ }^{62}$. No era extraño, pues, que fuera el presidente del Consejo de Ministros, como máxima autoridad política, quien tuviera la distinción de poder besar la mano a la reina antes de entregarle el discurso de apertura, un ritual que se mantuvo prácticamente hasta el final del reinado de Isabel II. En el fondo, era un acto de reconocimiento del poder político de la Corona, aunque limitado a su vez por las instituciones parlamentarias, con quienes compartía soberanía: no en balde, desde la década de 1830 el discurso ya no lo escribía el rey, sino los gobiernos y ellos tenían que dar cuenta del contenido, atendiendo la inviolabilidad de la figura de la reina, no sujeta a responsabilidad.

Por eso, el discurso de la Corona se entendió progresivamente como la presentación del programa de gobierno de los gabinetes de turno y el debate de contestación como la oportunidad de la oposición de valorar su acción ${ }^{63}$. En otras palabras, el discurso de apertura no era otro elemento más de pompa monárquica, sino un instrumento de debate político que se configuró como pieza básica del régimen de las dos confianzas. Da ejemplo de ello el editorial

${ }^{61}$ La ruta sufrió modificaciones con el tiempo. Por ejemplo, en 1858 recorría las calles Mayor y de Platerías, Plaza Mayor, calle de Atocha, calle de Carretas, Puerta del Sol y Carrera de San Jerónimo. Véase La Época, 2 de diciembre de 1858: 3.

62 BOURGOING y PEYRON, 1789, vol. 1: 87-89.

${ }^{63}$ MARCUELLO, 1986. DÍAZ MARÍN, 2018. 
de El Español ante la apertura de 1846. El diario dirigido por el moderado independiente Andrés Borrego canalizó sus reproches hacia el gobierno:

El discurso pronunciado por S. M. en el acto de apertura de las Cortes, es ni más ni menos que lo que nos figurábamos nosotros cuando, hablando de las vacilaciones del ministerio sobre escribir o no escribir ese documento, nos anticipábamos a consignar los términos en qué, caso de escribirse, estaría concebido. Una sola cosa le falta para ser enteramente tal como nosotros anunciábamos que sería, o por mejor decir que debía ser, y esa cosa es lo que llamábamos su dimisión ante el parlamento. [...] si el ministerio por un movimiento de ridículo orgullo o por una vana esperanza de alargar su existencia no ha tenido por conveniente plantear la cuestión de gabinete ante el parlamento, no por eso se ha visto menos obligado a confesar indirectamente por medio de una omisión que han pasado los tiempos en que le era lícito contar de antemano con el apoyo de la mayoría ${ }^{64}$.

Esta representación de la distribución del poder se daba en sintonía con la realidad política que se fraguó al calor del contexto descrito para la década de 1830 y que culminó con la conformación del proyecto político del Partido Moderado en la segunda mitad de la década de 1840. La formación vio en la Corona la institución capaz de ofrecer estabilidad al sistema político y mantener el orden público frente al Congreso, percibido como un organismo de elección popular y fuente de inestabilidad. Con la Constitución de 1845 se implantó la soberanía compartida entre la Corona y la cámara baja, desterrando la soberanía nacional introducida por la vía gaditana.

Veamos cómo se traducía este imaginario en los discursos de las aperturas de Cortes. En 1850, por ejemplo, Isabel II apeló de nuevo a la providencia como una de las bases en que se apoyaba su poder. Sin embargo, esta vez la Corona compartió dicho privilegio con las Cortes. Tales fueron sus palabras:

Como espero que continuarán, la paz interior, el respeto al Trono y a la Constitución de la Monarquía, y la confianza y la armonía entre los poderes públicos. Para conseguir tan noble objeto cuento con la mayor confianza, con la sabiduría y patriotismo de que tan señalados ejemplos han dado en todos tiempos las Cortes españolas; y cuento sobre todo con los auxilios de la Divina Providencia, que de tantos conflictos ha sacado hasta ahora a esta Nación grande y generosa ${ }^{65}$.

Esto revela las concesiones del moderantismo hacia la monarquía, que no emergía como una institución simbólicamente representativa de la soberanía nacional y, por lo tanto, dependiente de la voluntad de la población. Por el contrario, la Corona se presentaba con una naturaleza anterior al poder de la

${ }^{64}$ El Español, 1 de enero de 1847: 2.

${ }^{65}$ DSC: legislatura de 1845-46: 2-3, disponible en: https://app.congreso.es/est_sesiones/ [consultado el 8 de febrero de 2019]. 
población. Dadas las circunstancias, la reina y su entorno se vieron legitimados legalmente para actuar con autonomía, al margen de las instituciones parlamentarias.

Si bien es cierto que esta perspectiva que facultaba la autonomía de la Corona se vincula mayormente con los gobiernos del Partido Moderado, los gabinetes de la Unión Liberal no matizaron demasiado dicha posición. En realidad, los partidos conservadores del liberalismo español omitieron por lo general cualquier palabra que vinculara los políticos como acreedores de la ciudadanía. En los discursos de apertura, redactados por los políticos desde el Estatuto Real, se refirieron a sí mismos como diputados y senadores, sin más implicación. No fue hasta los últimos años del reinado de Isabel II que se encuentran formulaciones más connotadas, como «los representantes de la nación». Esta referencia implicaba una vinculación más explícita de las instituciones parlamentarias con la población, aunque el término «nación» no se tiene que asociar ya a la idea de sujeto político surgida del contexto gaditano de 1812, sino a una visión de comunidad desligada de este tipo de evocaciones políticas de las que huía el liberalismo posterior a la década de 1830.

Tampoco hay rastro del término «ciudadano». Hay que tener en cuenta que a medida que avanzó el siglo, y hasta el Sexenio Democrático, el concepto estaba cada vez más ligado a una idea de igualdad jurídica y política del individuo, que especialmente entre los sectores más avanzados implicaba una cierta noción de soberanía individual y colectiva materializada en la soberanía nacional ${ }^{66}$. Como indica Pérez Ledesma, a partir de la Constitución de 1837 el término desapareció de las constituciones españolas del siglo XIX — con la excepción del texto provisional de 1873 - , para dejar espacio a los «españoles» o a los «electores». Era una forma de evitar las evocaciones a la igualdad y a los derechos individuales ${ }^{67}$.

Asimismo, la voz «pueblo» siguió apareciendo en estos discursos asimilada a una idea de comunidad sometida aún a los dictados del monarca. El discurso de apertura de 1867 no dejaba lugar a dudas:

Asunto hermoso de admiración ofrece un gran pueblo que conserva al través de los siglos los caracteres esenciales de su individualidad como nación y guarda con perseverante empeño la limpieza de la fe heredada y el antiguo depósito de su honor y de su nombradía, sin negarse con todo eso a caminar por los nuevos espacios que incesantemente abre la Omnipotencia de Dios a la actividad del hombre y al logro de sus crecimientos y de sus prosperidades. Insigne posición es la del Monarca encargado de regir la gobernación del pueblo que en tamaña empresa está comprometido ${ }^{68}$.

${ }^{66}$ Sobre el concepto FERNÁNDEZ SEBASTIÁN, 2002.

${ }^{67}$ PÉREZ LEDESMA, 2007: 449.

${ }^{68}$ DSC: legislatura de 1867-68: 2-4, disponible en: https://app.congreso.es/est_sesiones/ [consultado el 8 de febrero de 2019]. 
Estas circunstancias fueron aprovechadas por la monarquía en los ceremoniales de apertura de Cortes para reforzar los intereses propios de la institución. Con respecto a los rituales desarrollados según la Constitución de 1812, la situación había dado un vuelco. La reina ya no tenía que someterse a los parlamentarios como representantes de la soberanía nacional; había recuperado importantes atribuciones políticas. Entre otras competencias destacadas podía nombrar y separar libremente a los ministros, tenía facultad para disolver las Cortes con el fin de arbitrar los posibles conflictos entre gobiernos y cámaras y disponía de la capacidad de veto sin límites sobre los acuerdos de ley establecidos en las instituciones parlamentarias ${ }^{69}$. Lo cierto es que era la responsable de nombrar los gobiernos y sus ministros y éstos tenían que darle cuentas, ya que podía cesarles. A pesar de ello, estaba condicionada a leer un discurso que le venía dado por el gobierno, y aunque no tenía que dar cuentas por él, en último término quien ponía un gabinete u otro era la monarquía. Es decir, también la Corona era corresponsable a ojos de la ciudadanía, no legalmente, pero sí podía ser juzgada moralmente por sus acciones, así lo demuestra la revolución de 1868.

Por eso, en el espacio del hemiciclo y durante el ritual, reina y políticos se situaban al mismo nivel, aunque Isabel II estaba en el centro y en el trono, o lo que es lo mismo, finalmente era quien decidía aún por encima de las instituciones parlamentarias. De hecho, en las aperturas de Cortes a lo largo del siglo XIX, los políticos únicamente se podían sentar después de recibir el permiso de los monarcas. Es decir, el ceremonial ratificaba simbólicamente el reparto efectivo del poder. Por aquel entonces, la monarquía de Isabel II ya no veía peligrar su continuidad por la amenaza carlista y se había consolidado el sistema monárquico constitucional con el modelo de soberanía compartida.

Las circunstancias indican la relación trazada entre monarquía y parlamentarismo, con una evidente relevancia de la primera institución. Ya ha señalado Isabel Burdiel, en razón del poder acumulado por la Corona en la Constitución de 1845 , que la cesión hecha era un reconocimiento a su papel en la identidad española, de manera que el pacto político suponía una amalgama entre nación y Corona ${ }^{70}$. Sin duda, este tipo de ceremoniales contribuían a ello, relacionando a la vez la imagen de las dos instituciones a ojos de la sociedad. Del mismo modo, según Jesús Millán y María Cruz Romeo, la continuidad a principios del siglo XX de este rol destacado de la monarquía - conservando la capacidad para disolver las Cortes tantas veces como quisiese - favorecía afianzar sus vínculos con la identidad, puesto que parecía emerger como el apoyo imprescindible para la supervivencia de la nación. No obstante, lo que provocó fue el

\footnotetext{
${ }^{69}$ MARCUELLO, 1986: 8.

${ }^{70}$ BURDIEL, 2010: 183-184.
}

Hispania, 2019, vol. LXXIX, n 261, enero-abril, págs. 99-126, ISSN: 0018-2141, e-ISSN: 1988-8368 https://doi.org/10.3989/hispania.2019.004 
cuestionamiento del poder del parlamento, dada su capacidad parar disolver las legislaturas de forma unilateral ${ }^{71}$.

Estas correspondencias no se circunscribían solo a la España liberal. También se identificó la reina Victoria de Inglaterra como símbolo de unos valores de identidad británica. Se la vinculó, desde una visión de domesticación de la monarquía, con su condición de mujer, gobernante y madre, perspectivas que a la vez le permitían conectar con la dirección y gobierno del imperio británico ${ }^{72}$. Asimismo, el ceremonial de apertura en Westminster, aunque con raíces anteriores, también sentó sus bases a mediados del siglo XIX y con el monarca como su protagonista.

David San Narciso ha explicado las ataduras entre la monarquía de Isabel II y la nación mediante el estudio de los ropajes de la reina ${ }^{73}$. En el caso de las aperturas de Cortes el análisis de sus atuendos también refrenda esta intencionalidad de representar una determinada idea de nación mediante la indumentaria. En la apertura de 1858 llevaba un vestido blanco «con los castillos y leones de España primorosamente bordados en oro $\gg^{74}$. Es decir, se vestía con las armas heráldicas de Castilla para representar simbólicamente una determinada idea de nación, a la vez que quería asentar de esta manera sus vínculos con la población. Ya hemos visto como era así en el caso de la reina regente, e Isabel II redundó en esta dirección. Las aclamaciones populares, cada vez más, se centraron únicamente en la Corona ${ }^{75}$, y olvidaban, por omisión, las referencias a la nación y el gobierno.

Pero especialmente el vestuario refuerza la voluntad de remarcar su posición de poder, con la idea de que la institución marchaba incluso de manera independiente a las cámaras parlamentarias. En el mismo acto de 1858 Isabel II cubría el citado vestido blanco con un manto bordado con medallones de oro, con el árbol genealógico real de España ${ }^{76}$. La pieza remitía a la larga tradición monárquica española, vinculándola al poder de manera autónoma a cualquier otra institución.

Estas intencionalidades se repetían en la escenificación pública de su poder. En la apertura de Cortes de 1850 la reina vestía un traje de tul blanco cubierto con un manto de terciopelo carmesí tachonado de oro. Lo adornaba con una diadema de perlas, además de llevar el pecho cubierto de brillantes ${ }^{77}$. La cereza en el pastel la ponía la exhibición de la corona y el cetro, que se distin-

\footnotetext{
71 MILLÁN y ROMEO, 2013.

72 LANGLAND, 1997.

73 SAN NARCISO, 108 (Madrid, 2017): 203-230.

${ }^{74}$ La Época, 2 de diciembre de 1858: 3.

75 El Católico, 1 de noviembre de 1850: 5.

${ }^{76}$ La Época, 2 de diciembre de 1858: 3.

${ }^{77}$ La España, 1 de noviembre de 1850: 3. El Heraldo, 1 de noviembre de 1850: 2.
} 
guían en el carruaje de la reina para que todo el mundo los observara ${ }^{78}$. Eran símbolos de poder y distinción, del mismo modo que también transmitían autoridad las joyas y atuendos utilizados. En todo caso, el elemento de la corona, por encima de todo, se erigía como emblema del poder de la realeza. De la misma manera, el color carmesí, como hemos comentado con el negro, también puede interpretarse como signo de poder, los cardenales y sus atuendos rojos son ejemplo de ello.

Además, el rey consorte llevaba el uniforme de capitán general, como icono de su rango. No era casualidad, teniendo en cuenta que los parlamentarios ya no tenían el vestido negro como indumentaria preferida, sino que priorizaban los uniformes. Tal y como rezaba el reglamento del congreso de los diputados de 1847, y el de 1866 ratificaría:

... los diputados que no tengan uniforme o traje particular, se presentarán con vestido negro en los días en que el Rey, el Sucesor a la Corona, el Regente o Regencia asistan a las Cortes, y los de galas mayores; y del mismo usarán para ir en Diputación al Palacio de S. M. ${ }^{79}$.

Así, ante la asistencia de otros capitanes generales con uniforme o de otros militares de rango inferior, el rey sobresalía por encima del resto, ya que representaba el máximo escalafón del ejército. A él le correspondía, según el artículo 45.5 de la Constitución de 1845, disponer de la fuerza armada, distribuyéndola como más le conviniera ${ }^{80}$.

\section{¿Existió ALTERNATIVA ALGUNA A UN CEREMONIAL CONDUCIDO POR LA CORONA?}

A lo largo del reinado de Isabel II y durante el Sexenio Democrático se distinguen con claridad dos modelos confrontados de legitimidades de poder ciñéndonos exclusivamente a los partidos de gobierno-: por un lado, un modelo liberal conservador, encarnado por los gobiernos del Partido Moderado y en parte por los de la Unión Liberal; por el otro, un modelo liberal progresista, que representaban los gobiernos del Partido Progresista.

Se ha hecho hincapié en el modelo conservador, que se caracterizó por la cesión de relevantes poderes a la Corona. Por el contrario, la concepción de la representación del liberalismo progresista era más integradora. Es de sobras conocido que el Partido Progresista, a pesar de compartir con el liberalismo

\footnotetext{
78 El Popular, 1 de noviembre de 1850: 1.

79 CASADO, 2016: 197. Reglamento del Congreso de los Diputados y ley electoral, 1866: 43-44.

${ }^{80}$ Constitución española de 1845, disponible en: http://www.congreso.es/docu/constituciones/1845/1845_cd.pdf [consultado el 12 de julio de 2018].
} 
conservador el modelo basado en la ciudadanía propietaria, deseaba extender la esfera política a una mayor participación ciudadana, ya fuera con la ampliación del sufragio censitario, con el mantenimiento de la milicia nacional o con otros recursos similares que permitieran implicar a más gente en la esfera política, aunque fuera también con restricciones a la mayoría de la población. Sin embargo, ¿este modelo representaba una alternativa al tipo de ceremonial descrito en tiempo de dominio conservador?

La respuesta es negativa, teniendo en cuenta que a partir de la inauguración del palacio del Congreso de los Diputados en 1850 y a lo largo del siglo XIX el formato del ceremonial apenas cambió. Isabel II, y más adelante su hijo Alfonso XII, seguidos de una comitiva real, se desplazaban del Palacio Real al Congreso. A pesar de ello, es cierto que durante períodos de gobierno progresista, como por ejemplo el Bienio Progresista (1854-56), se estuvo a punto de prescindir de la sesión regia de apertura a Cortes. Hubo un intenso debate en la prensa $^{81}$, y posiciones encontradas entre las distintas sensibilidades progresistas $^{82}$, pero finalmente el gobierno se decantó por mantener la misma fórmula. Tanta era la vinculación de la monarquía con el acto, que incluso en las Cortes revolucionarias de 1869 se copió el tipo de ceremonial, salvo que se hizo sin rey. En su lugar, el gobierno provisional fue el protagonista del desfile: salió del Palacio de la Presidencia hasta el Congreso, pasando por las calles de Alcalá, Puerta del Sol y Carrera de San Jerónimo. Además, el discurso de inauguración fue leído por el presidente del gobierno ${ }^{83}$.

En lugar de aprovechar la ocasión para renovar el ritual o dar más protagonismo a la población, se repitió el mismo formato, cambiando el monarca por el presidente del gobierno. El hecho de reproducir el mismo tipo de evento, salvo por la ausencia de la Corona, implicaba una referencia por omisión a su papel protagonista en estos actos $y$, por lo tanto, contribuía a legitimar su estrecha vinculación con el sistema parlamentario español. Prueba de ello era el papel preeminente en los ceremoniales de apertura de Cortes. Solo en la legislatura republicana de 1873-74 se introdujo un ritual con una estructura manifiestamente alternativa a la practicada hasta ese momento. Después de la lectura del discurso inaugural por parte del presidente, se concibió un desfile de tropas y de voluntarios de la república que intentaba ofrecer a la población un papel activo y un formato que se alejaba del reproducido hasta entonces, con el rey en el epicentro de la festividad y un público más pasivo ${ }^{84}$.

A fin de cuentas, también el liberalismo representado por el Partido Progresista vio en la monarquía una institución clave para la consolidación del

\footnotetext{
${ }^{81}$ Consúltese, por ejemplo, La Época, 16 de octubre de 1854: 2.

82 BURDIEL, 2013.

${ }^{83}$ Gaceta de Madrid, 10 de febrero de 1869.

${ }^{84}$ La Esperanza, 2 de julio de 1873: 2.
}

Hispania, 2019, vol. LXXIX, nº 261, enero-abril, págs. 99-126, ISSN: 0018-2141, e-ISSN: 1988-8368 https://doi.org/10.3989/hispania.2019.004 
sistema constitucional y por eso estuvo de acuerdo en concederle un papel relevante en la política, como demuestran los ceremoniales aquí considerados. A pesar de coincidir con las sensibilidades conservadoras en la relevancia de la monarquía, para los progresistas su funcionalidad no era la misma. Como nos descubre Isabel Burdiel, su voluntad era nacionalizar a la monarquía a partir de su sujeción a las instituciones parlamentarias ${ }^{85}$, o sea limitarla a una función más simbólica que efectiva.

En consonancia con ello se muestra el contenido de los discursos de apertura. Eso es, si como hemos visto en etapas moderadas las referencias a los representantes políticos pasaban por los términos no connotados del tipo «diputado» $\mathrm{y}$ «senador», o como mucho, «representantes de la nación», durante mandatos progresistas se introdujeron conceptos que intentaban integrar un conjunto más amplio de la población. Es el caso de la expresión «elegidos del pueblo», usada en 1854 y 1869 . Vale la pena reproducir parte del discurso de apertura de Cortes de 1869:

... pero deshechas felizmente las trabas, gracias al poderoso esfuerzo de la revolución que hoy nos congrega, y después de una lucha obstinada y casi sin respiro durante sesenta años entre la idea nueva y la caduca, vosotros, elegidos del pueblo, estáis llamados á construir, por decirlo así, la futura ciudad sobre el ilustre y esclarecido suelo de la antigua ${ }^{86}$.

En este caso, el concepto «pueblo» además de referirse al conjunto de la población implicaba a los sectores sociales más humildes. Ante la introducción del sufragio universal masculino se abrió la puerta a la inclusión política de todos los hombres mayores de edad, a través del ejercicio del voto. Así, los diputados ya no actuaban solo como representantes de la nación política, asociada únicamente a los ciudadanos propietarios, sino que eran delegados de todo el conjunto de hombres españoles, entendidos como ciudadanos activos.

Es decir, ya no era la población quien se sometía a los designios de la monarquía, sino ésta quien debía respetar a la nación y, por consiguiente, someterse a su poder. La soberanía nacional volvía a recuperarse como fundamento del sistema político. En otras palabras, el Partido Progresista concebía la monarquía como un poder derivado de la soberanía nacional, alejado de las amplias capacidades que el moderantismo le había concedido con la Constitución de $1845^{87}$. En todo caso, como subraya María Cruz Romeo, durante el Sexenio Democrático no se corrigió del todo el modelo de doble confianza, puesto que el rey

${ }^{85}$ BURDIEL, 2013.

${ }^{86}$ DSC: legislatura de 1869-71: 1-3, disponible en: https://app.congreso.es/est_sesiones/ [consultado el 8 de febrero de 2019].

${ }^{87}$ ROMEO, 2007. BURDIEL, 2013. 
mantuvo ciertas competencias, como por ejemplo el veto a algunos proyectos de ley o la capacidad de nombrar al gobierno ${ }^{88}$.

\section{REFLEXIONES FINALES}

El presente artículo ha analizado los actos de apertura de las Cortes españolas del siglo XIX como festividades que implicaban formas simbólicas de representación política y que manifestaban el papel cambiante de la monarquía y de las instituciones parlamentarias en función del contexto político.

En su configuración, el acto de apertura de Cortes se inspiró en los rituales de escenificación del poder de las fiestas cortesanas modernas. Es el caso de los desfiles públicos de la Corona y de su comitiva real, que tomaron como ejemplo el modelo de Antiguo Régimen y se desplegaron sin la presencia de representantes políticos. Asimismo, la posición central de la reina en el congreso - sentada en un trono- - y su situación de poder, reconocida por prácticas como el besamanos, eran elementos que reconstruían los ceremoniales de época moderna. Algunas de estas prácticas permanecieron en el tiempo como indisociables al acto, particularmente la marcha real, y otras desaparecieron, como el besamanos lo hizo a partir de 1875 .

El ritual, por lo tanto, se adaptó a las circunstancias políticas para evocar las relaciones de poder conforme al contexto de cada momento, pero fueron particularmente los sujetos involucrados en él quienes dotaron de simbolismo la apertura en función de sus intereses. Así, los representantes políticos intentaron bajo la Constitución de 1812 situar al rey en una posición sometida a las instituciones parlamentarias, simbolizando la primacía de la soberanía nacional. Sin ir más lejos, era el presidente del parlamento quien se dirigía al rey y le permitía añadir unas palabras. Con la progresiva consolidación de la soberanía compartida, los parlamentarios cedieron más protagonismo a la Corona, como elemento central de las aperturas de Cortes, pero al mismo tiempo limitaron su capacidad de decisión al redactar el discurso, que se convirtió a su vez en un instrumento de control de los gobiernos identificado con el régimen parlamentario de las dos confianzas.

Diputados y senadores escenificaron su posición de poder político, y su estatus político y social, a través de su indumentaria - con uniformes y/o vestidos de negro-, legitimando así su posición ante la población española. De hecho, el papel de la sociedad fue más bien pasivo, pero su interacción con la monarquía y los representantes políticos confería legitimidad a los dirigentes.

En cualquier caso, en estos actos intencionales sobresalió por encima de todo el papel de la monarquía, quien interpretó las aperturas como una

\footnotetext{
${ }^{88}$ ROMEO, 2002.
} 
oportunidad. Fue una ocasión para consolidar su posición en el sistema liberal, cuando la línea sucesoria fue discutida por el carlismo. Adaptó sus rituales y se posicionó en el ceremonial como un nexo de unión entre la población y las instituciones parlamentarias. No en balde acabó por ser el elemento central, con el desfile como su insignia. Eso le permitió conectar con la población.

Estas circunstancias proyectaron a la monarquía como un elemento de nacionalización, favorecida por la destacada posición que las distintas sensibilidades políticas le otorgaron desde distintas funcionalidades: desde un papel simbólico de los progresistas a un amplio rol competencial de los moderados. Con el paso de los años, muy pocas sensibilidades políticas discutieron la participación de la Corona en estos actos. Se interpretaba la institución como un elemento de cohesión que, a diferencia de las distintas sensibilidades políticas que implicaban fraccionamiento social y político, era capaz de representar a la nación en su conjunto. Por eso en las aperturas de Cortes no se detecta prácticamente ninguna alternativa al ritual que sitúa a la Corona como epicentro. El desgaste de la figura de Isabel II — por sus escándalos y las vinculaciones de la familia con los negocios ${ }^{89}$ - puso a debate su participación en 1854, aunque sin revocarla, e incluso en 1869 el ceremonial se materializó evocando al modelo consolidado con el desfile de la reina, aunque sin ella. La excepción la pusieron las Cortes republicanas de 1873-74, que formularon una alternativa que no cuajó.

Por eso, no resulta extraño que el ceremonial apareciera también como una situación inmejorable para proyectar simbólicamente el poder de la monarquía al margen de las instituciones políticas. Los vestidos, las joyas y los ornamentos aludían al deseo de la Corona de ostentar poder y de remarcar su posición autónoma en su ejercicio. El manto con el árbol genealógico es un claro ejemplo de dicha intencionalidad. Este atuendo invoca la larga trayectoria histórica de la monarquía, que transciende la de las instituciones parlamentarias.

Sin embargo, el acto de apertura no favoreció exclusivamente a las voluntades monárquicas $\mathrm{y}$, de hecho, se consolidó como instrumento propio del debate parlamentario. Aunque pronunciado por la reina, el discurso de la Corona se entendió como la presentación de un programa de gobierno y su contestación como una herramienta de control político por el Congreso. Otro debate sería el papel interesado que jugó Isabel II en la elección de determinados gobiernos, y como ello influyó en su caída. Al fin y al cabo, Isabel II tuvo que dejar el trono, pero en el ceremonial de apertura de Cortes pervivió el mismo modelo que concedía tanto a la monarquía un papel protagonista como a las instituciones parlamentarias un poder efectivo que no volvería a ser cuestionado en décadas.

${ }^{89}$ BURDIEL, 2010.

Hispania, 2019, vol. LXXIX, n 261, enero-abril, págs. 99-126, ISSN: 0018-2141, e-ISSN: 1988-8368 https://doi.org/10.3989/hispania.2019.004 


\section{BibliOgR AFÍA}

Alonso, Gregorio, "Ciudadanía católica y ciudadanía laica en la experiencia liberal», en Manuel Pérez Ledesma (dir.), De súbditos a ciudadanos: Una historia de la ciudadanía en España, Madrid, Centro de Estudios Políticos y Constitucionales, 2007: 165-192.

Álvarez Junco, José, «En torno al concepto de "pueblo”. De las diversas encarnaciones de la colectividad como sujeto político en la cultura política española contemporánea», Historia Contemporánea, 28 (Leioa, 2004): 83-94.

Argüelles, Agustín de, Examen histórico de la reforma constitucional que hicieron las Cortes Generales y Extraordinarias desde que se instalaron en la Isla de León el día 24 de septiembre de 1810, hasta que cerraron en Cádiz sus sesiones el día 14 del propio mes de 1813, Londres, Imprenta de Carlos Wood e hijo, 1835, vol. 1.

Artola, Miguel, «La Monarquía parlamentaria», Ayer, 1 (Madrid, 1991): 105-123.

Best, Heinrich y Cotta, Maurizio (eds.), Parliamentary representatives in Europe 1848-2000: Legislative recruitment and careers in eleven European countries, Oxford, Oxford University Press, 2000.

Best, Heinrich y Cotta, Maurizio (eds.), Democratic Representation in Europe: Diversity, Change and Convergence, Oxford, Oxford University Press, 2007.

Bourgoing, Jean-François y Peyron, Jean-François, Travels in Spain, Londres, G. G. J. y J. Robinson, 1789, vol. 1.

Burdiel, Isabel, Isabel II: Una biografía (1830-1904), Madrid, Taurus, 2010.

Burdiel, Isabel, «Monarquía y nación en la cultura política progresista. La encrucijada de 1854», en Encarna García Monerris, Mónica Moreno Seco y Juan Ignacio Marcuello Benedicto (eds.), Culturas politicas monárquicas en la España liberal: Discursos, representaciones y prácticas (1808-1902), Valencia, Publicacions de la Universitat de València, 2013: 213-232.

Calatayud, Salvador, Millán, Jesús y Romeo, María Cruz (coords.), Estado y periferias en la España del siglo XIX. Nuevos enfoques, Valencia, Publicacions de la Universitat de València, 2009.

Campos, Jorge (ed.), Memorias de D. Antonio Alcalá Galiano publicadas por su hijo, Madrid, Atlas, 1955.

Casado Trigo, Manuel, Historia del protocolo en las Cortes Generales Españolas, Alcorcón, Sanz y Torres, 2016.

Casals Bergés, Quintí, La representación parlamentaria en España durante el Primer Liberalismo (1810-1836), Lleida/Cádiz, Universitat de Lleida/Universidad de Cádiz, 2014.

Chávarry García, Francisco Javier, El secreto de la liturgia: Claves para vivir su misterio, Lima, Paulinas, 2002.

Clark, Elizabeth A., History, theory, text: Historians and the Linguistic Turn, Cambridge, Harvard University Press, 2004.

Comenge, Rafael, Antología de las Cortes de Cádiz, Madrid, Hijos de J. A. García, 1909.

De la Fuente Monge, Gregorio, Los revolucionarios de 1868: elites y poder en la España liberal, Madrid, Marcial Pons, 2000. 
Díaz Marín, Pedro, Política de Estado: Los discursos de la Corona durante la Década Moderada (1844-1854), Sant Vicent del Raspeig, Publicacions de la Universitat d'Alacant, 2018.

Estrada Sánchez, Manuel, El significado político de la legislación electoral en la España de Isabel II, Santander, Servicio de Publicaciones de la Universidad de Cantabria, 1999.

Fernández Domínguez, Arturo, Leyes electorales españolas de diputados a Cortes en el siglo XIX: Estudio histórico y jurídico-político, Madrid, Civitas, 1992.

Fernández Sebastián, Javier, «Ciudadanía», en Javier Fernández Sebastián y Juan Francisco Fuentes (dirs.), Diccionario político y social del siglo XIX español, Madrid, Alianza Editorial, 2002: 139-143.

Fernández Sebastián, Javier y Fuentes, Juan Francisco (dirs.), Diccionario político y social del siglo XIX español, Madrid, Alianza Editorial, 2002.

García Monerris, Encarna y García Monerris, Carmen, Las cosas del rey: Historia política de una desavenencia (1808-1874), Madrid, Akal, 2015.

García Monerris, Encarna, Moreno Seco, Mónica y Marcuello Benedicto, Juan Ignacio (eds.), Culturas políticas monárquicas en la España liberal: Discursos, representaciones y prácticas (1808-1902), Valencia, Publicacions de la Universitat de València, 2013.

García Sebastiani, Marcela y Marcilhacy, David, «Celebrating the Nation: 12 October, from 'Day of the Race' to Spanish National Day», Journal of Contemporary History, 52/3 (Essex, 2017): 731-763.

Garrorena Morales, Ángel, Representación política y Constitución democrática: (Hacia una revisión crítica de la teoría de la representación), Madrid, Civitas, 1991.

Handelman, Don, Models and mirrors: Towards an anthropology of public events, Cambridge, Cambridge University Press, 1990.

Ihl, Olivier, La fête républicaine, París, Gallimard, 1996.

Joseph, Nathan y Alex, Nicholas, «The Uniform: A Sociological Perspective», American Journal of Sociology, 77/4 (Chicago, 1972): 719-730.

Jurado Sánchez, José, Marín Perellón, Francisco José, De los Reyes Leoz, José Luis y Del Río Barredo, María José, «Espacio urbano y propaganda política las ceremonias públicas de la monarquía y Nuestra Señora de Atocha», en Santos Madrazo y Virgilio Pinto (eds.), Madrid en la época moderna: Espacio, sociedad y cultura, Madrid, UAM/Casa de Velázquez, 1991: 219-264.

Kertzer, David I., Ritual, politics, and power, New Haven-Londres, Yale University Press, 1988.

Knights, Mark, «Participation and representation before democracy: Petitions and addresses in premodern Britain», en Ian Shapiro, Susan C. Stokes, Elisabeth Jean Wood y Alexander S. Kirshner (eds.), Political Representation, Cambridge, Cambridge University Press, 2009: 35-57.

La Parra López, Emilio (coord.), La imagen del poder: Reyes y regentes en la España del siglo XIX, Madrid, Síntesis, 2011.

La Parra López, Emilio, Fernando VII: Un rey deseado y detestado, Barcelona, Tusquets, 2018.

Hispania, 2019, vol. LXXIX, n 261, enero-abril, págs. 99-126, ISSN: 0018-2141, e-ISSN: 1988-8368

https://doi.org/10.3989/hispania.2019.004 
Langland, Elizabeth, «Nation and nationality: Queen Victoria in the developing narrative of Englishness», en Margaret Homans y Adrienne Munich (eds.), Remaking Queen Victoria, Cambridge, Cambridge University Press, 1997: 13-32.

Luengo Sánchez, Jorge, «Representar la monarquía: festividades en torno a la reina niña (1833-1846)», en Encarna García Monerris, Mónica Moreno Seco y Juan Ignacio Marcuello Benedicto (eds.), Culturas políticas monárquicas en la España liberal: Discursos, representaciones y prácticas (1808-1902), Valencia, Publicacions de la Universitat de València, 2013: 109-129.

Luján, Oriol, «El síndrome del escaño vacío: Absentismo y representación política en la España liberal de mediados del siglo XIX», Revista de Estudios Políticos, 176 (Madrid, 2017): 47-77.

Marcuello Benedicto, Juan Ignacio, La práctica parlamentaria en el reinado de Isabel II, Madrid, Congreso de los Diputados, 1986.

Mariot, Nicolas, «Qu'est-ce qu'un 'enthousiasme civique'? Sur l'historiographie des fêtes politiques en France après 1789», Annales. Histoire, Sciences Sociales, 1 (París, 2008): 113-139.

Medina Plana, Raquel, Soberanía, monarquía y representación en las Cortes del Trienio, Madrid, Fundación Universitaria Española, 2005, vol. 1.

Millán, Jesús, «La monarquía española durante la época de formación de los Estados nacionales en Europa», en Simposio «Monarquía y constitución en la España contemporánea», Sevilla, Universidad de Sevilla, 2016.

Millán, Jesús y Romeo Mateo, María Cruz, «Modelos de monarquía en el proceso de afirmación nacional de España, 1808-1923», Diacronie: Studi di Storia Contemporanea, 16/4 (Bolonia, 2013), disponible en: www.studistorici.com/2013/12/29/ millan-romeo_numero_16 [consultado el 26 de enero de 2018].

Moreno Luzón, Javier y Núñez Seixas, Xosé Manoel, Los colores de la patria. Símbolos nacionales y vida política en la España contemporánea, Madrid, Tecnos, 2017.

Núñez Seixas, Xosé Manoel (ed.), «La construcción de la identidad regional en Europa y España (siglos XIX y XX)», Ayer, 64 (Madrid, 2006).

Ozouf, Mona, La fête révolutionnaire 1789-1799, París, Gallimard, 1976.

Palacios Cerezales, Diego, «Ejercer derechos: Reivindicación, petición y conflicto», en María Cruz Romeo y María Sierra (coords.), La España liberal, 1833-1874, Madrid/Zaragoza, Marcial Pons/Prensas de la Universidad de Zaragoza, 2014: 253-285.

Pastoreau, Michel y Simonnet, Dominique, Le petit livre des couleurs, París, Seuil, 2014.

Pérez Garzón, Juan Sisinio, Las Cortes de Cádiz: El nacimiento de la nación liberal (1808-1814), Madrid, Síntesis, 2007.

Pérez Ledesma, Manuel, «El lenguaje de la ciudadanía en la España contemporánea», en Manuel Pérez Ledesma (dir.), De súbditos a ciudadanos: Una historia de la ciudadanía en España, Madrid, Centro de Estudios Políticos y Constitucionales, 2007: 445-481.

Portillo Valdés, José María, «Nación», en Javier Fernández Sebastián y Juan Francisco Fuentes (dir.), Diccionario político y social del siglo XIX español, Madrid, Alianza, 2002: 468-476. 
Presno Linera, Miguel Ángel, Leyes y normas electorales en la historia constitucional española, Madrid, Iustel, 2013.

Roca Vernet, Jordi, «Fiestas cívicas en la revolución liberal: Entusiasmo y popularidad del régimen», Historia Social, 86 (Valencia, 2016): 71-90.

Romeo Mateo, María Cruz, «Lenguaje y política del nuevo liberalismo: moderados y progresistas, 1834-1845», Ayer, 29 (Madrid, 1998): 37-62.

Romeo Mateo, María Cruz, «Parlamentarismo», en Javier Fernández Sebastián y Juan Francisco Fuentes (dirs.), Diccionario político y social del siglo XIX español, Madrid, Alianza Editorial, 2002: 495-501.

Romeo Mateo, María Cruz, «La ficción monárquica y la magia de la nación en el progresismo isabelino», en Ángeles Lario (ed.), Monarquía y República en la España contemporánea, Madrid, Biblioteca Nueva, 2007: 107-125.

San Narciso Martín, David, «Ceremonias de la monarquía isabelina. Un análisis desde la historia cultural», Revista de Historiografía, 21 (Madrid, 2014): 191-207.

San Narciso Martín, David, «Viejos ropajes para una nueva monarquía. Género y nación en la refundación simbólica de la Corona de Isabel II (1858-1866)», Ayer, 108 (Madrid, 2017): 203-230.

Santirso, Manuel, Progreso y libertad: España en la Europa liberal (1830-1870), Barcelona, Ariel, 2008.

Sierra, María y Peña, María Antonia, «La representación política en el primer liberalismo: herencia y olvido de las Cortes de Cádiz», en Alberto Ramos Santana (coord.), La Constitución de 1812. Clave del liberalismo en Andalucía, Sevilla, Centro de Estudios Andaluces, 2012: 57-82.

Spiegel, Gabrielle M. (ed.), Practicing history: New directions in historical writing after the Linguistic Turn, Londres-New York, Routledge, 2005.

Suárez, Federico, Las Cortes de Cádiz, Madrid, Rialp, 1982.

Varela Suanzes-Carpegna, Joaquín, La Teoría del Estado en las Cortes de Cádiz: orígenes del constitucionalismo hispánico, Madrid, Centro de Estudios Políticos y Constitucionales, 2011.

Veiga Alonso, Xosé Ramón, «Poderes locales y construcción del Estado en el siglo XIX (1808-1874)», Ayer, 108 (Madrid, 2017): 285-302.

Weller, Thomas, «Símbolos, imágenes, rituales: El lenguaje simbólico del poder en la Europa del Antiguo Régimen», Memoria y civilización, 13 (Pamplona, 2010): 9-33.

Recibido: 30/01/2018

Aceptado: 24/09/2018

Hispania, 2019, vol. LXXIX, n 261, enero-abril, págs. 99-126, ISSN: 0018-2141, e-ISSN: 1988-8368

https://doi.org/10.3989/hispania.2019.004 